\title{
RENASCENDO DAS CINZAS. UM HISTÓRICO DA PRESENÇA DOS CAYAPÓ-PANARA EM GOIÁSE NO TRIÂNGULO MINEIRO*
}

Odair Giraldin**

\section{Resumo}

Na história da ocupação do Centro-Ceste brasileiro, sobretudb a região de Goiás, os índios Cayapó aparecem como um dos povos indígenas que ofereceram maior resistência à fixação dos não-indígenas na região. As poucas informaçães históricas scbre eles davam-nos como um povo extinto a partir do início do século XX. Neste artigo, no entanto, apresento fontes documentais que indicam que os Cayapó são os antepassados dos atuais Panara (que vivem no sul do estado do Pará). Como evidência dessa relação, apresento dados lingüísticos, através de um excelente vocabulário dos Cayapó coligido por um morador da cidade de Uberaba (MG), em 1918.

Palavras-chave: história indígena; Cayapó Meridional; Panara; Brasil Central.

\section{A fatalidade da extinção}

No início do século $X X$, com a expansão da agricultura cafeeira, 0 governo do estado de São Paulo viu-se necessitado de investir recursos para explorar o interior do seu território, boa parte do qual era ainda desconhecido ehabitado por grupos indígenas que viviam autonomamente, isto é, sem contato permanente com a população não-índia. Para real izar essas expedições, foi criada a Comissão Geográfica e Geológica do

* Este texto é uma ampliação de uma palestra apresentada em U beraba (M G) em 22 de abril de 1998, com o seguinte título: U m resgate histórico. 0 encontro de Alexandre de Souza Barbosa e os Cayapó-Panara no Triângulo Mineiro.

** Doutor em Ciências Sociais (ênfase em Etnologia Indígena) pela Unicamp. Professor do curso de História da Universidade do Tocantins (Unitins), campus de Porto Nacional ( $\mathrm{TO}$ ). 
Estado de São Paulo. Essa comissão explorou os Rios Feio e do Peixe, na região central do estado, e, em 1910, foi incumbida da tarefa de explorar o Rio Grande e seus afluentes. A o chegar na altura da divisa entre São Paulo e o Triângulo M ineiro, próximo à Cachoeira Á gua Vermelha, na margem direita daquele rio, encontrou um pequeno grupo de índios conhecidos como Cayapó. ${ }^{1}$ Tratava-se de um grupo relativamente pequeno, com cerca de trinta pessoas, despertando muito interesse naquel es pesquisadores, que não deixaram maiores informações sobre eles. A penas a foto de um garoto ficou como testemunho do encontro. ${ }^{2}$

Essa informação foi considerada por muito tempo como a última que se teve sobre esse grupo indígena, conhecido também na literatura antropológica como K ayapó do sul ou K ayapó meridionais. ${ }^{3}$ Conforme veremos no final deste artigo, aqueles Cayapó das margens do Rio Grande chamaram a atenção de um morador de U beraba: A lexandre de Souza Barbosa. Ele trabalhava como agrimensor na região e, do encontro com os Cayapó, B arbosa coligiu um extenso vocabulário da língua fal ada por aquele povo, escrevendo também um trabal ho sobre a história do grupo.

A distinção entre os grupo do sul e do norte foi inicialmente proposta por Paul Ehrenreich (1892, p. 28-38), no final do século XIX. Propondo uma divisão e distribuição das "tribos" brasileiras, ele assim classificou os povos de língua J ê: separou os J ê em orientais, centrais e ocidentais. Entre os primeiros incluiu os Botocudo; entre os segundos os Cayapó e os $X$ avante e, entre os terceiros, os Suyá. Dividiu também os Kayapó em três grupos: do norte, do sul e ocidentais. Entre os do norte, incluiu os Xikrin, Gradaú, Gaviões, A pinajé, K rahô e demais Timbiras; entre os ocidentais, englobou os Suyá e os A kwen; no grupo do sul, incluiu os Kayapó meridionais e os K aingang.

Duas correntes diferentes procuraram fazer a relação entre os Kayapó setentrionais e os meridionais. Há uma que acredita que os K ayapó setentrionais são parte dos meridionais, que teriam se deslocado para sua atual região (norte de M ato Grosso e sul do Pará) a partir dos conflitos advindos do contato com a sociedade colonial, principalmente com a ocupação do B rasil Central. Entre os que defendem essa hipótese, podemos destacar, entre outros, $\mathrm{F}$ rancis $\mathrm{C}$ astel nau. Viajando pelo interior do B rasil em meados do século XIX, ele considerou os Gradaú, grupo 
habitante ao norte da I Iha do B ananal, como sendo um subgrupo Kayapó (Castel nau, 1949, p. 33). M achado de Oliveira (1862, p. 506), personagem conhecido pelo seu envolvimento político no B rasil oitocentista - foi diretor dos aldeamentos de São Paulo e presidente da província do M aranhão -, escreveu em meados do século XIX um histórico sobre os Cayapó, assumindo a mesma hipótese de Castelnau. Compartilha ainda dessa corrente o historiador paulista M ário N eme. $N$ a década de 1960, como pesquisador assíduo do A rquivo Público do Estado de São Paulo (onde chegou a assumir funções administrativas), ele realizou pesquisas documentais a partir das quais escreveu ( $\mathrm{N}$ eme, 1969) uma história dos Cayapó.

A segunda corrente não trata relações de homologia entre os $\mathrm{K}$ ayapó setentrionais e os K ayapó meridionais e considera o grupo meridional como extinto. Contrário à tese de homologia, Nimuendajú (1952) fazia distinção entre K ayapó do norte e do sul ao afirmar que, de um exame da cultura, da língua e da história dos dois grupos, poder-se-ia perceber que, embora aparentadas, seriam claramente diferentes e não poderiam ser consideradas como derivadas uma da outra (N imuendajú, 1952, p. 427). Darcy Ribeiro também compartilhava dessa opinião. A o escrever um de seus livro mais conhecidos ( 0 s índios e a civilização), na década de 1960, ele afirmou que os "K aiapó Meridionais desapareceram sem deixar vestígios", com exceção do nome dado ao Rio Caiapó e à serra que corta seu antigo território, conhecido como Caiapônia, no sul de Goiás (Ribeiro, 1989, p. 71).

$\mathrm{N}$ ão foi sem razão que se acreditou que eles estavam extintos. Afinal, os Cayapó viveram e experimentaram todo um processo de invasão da região sul de $G$ oiás, do Triângulo $M$ ineiro, leste de $M$ ato $G$ rosso e norte de São Paulo, a partir do início do século XV III. A giram com ações guerreiras que os tornaram conhecidos como um dos grupos mais temidos e, em decorrência, mais intensamente combatidos durante o século XVIII e XIX em todo o B rasil Central.

Com a descoberta das minas de ouro, ocorridas em Goiás por volta de 1720, ocorreu uma migração colonial acelerada para a região, fato já anteriormente verificado em M inas Gerais (1693-1695) e Cuiabá (1718). Os primeiros garimpos localizavam-se nas margens do Rio Vermelho, originando a fundação de Vila Boa, atual cidade de Goiás. 
Nesse processo de invasão do território, desapareceu rapidamente o grupo Goiá, da família Jê, antigo habitante da região.

No processo de tentar incessantemente encontrar novos garimpos, tanto para suprir a necessidade da demanda crescente de novos mineradores, quanto pelo esgotamento natural das jazidas existentes, os aventureiros espalhavam-se por várias partes da região. 0 próprio descobridor das minas de Goiás, B artolomeu Bueno da Silva, conhecido como A nhangüera, explorando a região dos Rios Claro e Pilões, neles descobriu diamantes. M as não pôde levar adiante a exploração das pedras preciosas porque aquele tipo de atividade era um monopólio da coroa portuguesa (Prado Jr, 1992, p. 181-185) e também devido à presença intimidadora dos Cayapó na área.

A intensificação da exploração mineira, crescente nos primeiros anos, fez aumentar também o fluxo comercial entre Vila B oa e São Paulo. Esse comércio era feito por via terrestre, por uma estrada que ficou conhecida como "caminho de Goiás". Ela atravessava todo o sul de Goiás, 0 atual Triângulo M ineiro (pertencente a G oiás até 1806), também parte da área de ocupação tradicional dos Cayapó, até chegar em São Paulo.

A presença desses elementos estranhos dentro do território deu início ao processo de conflito armado entre Cayapó e "brancos". Para tentar manter o "caminho de Goiás" em segurança para os viajantes, 0 governador de São Paulo, D. L uís de M ascarenhas, contratou A ntônio Pires de Campos, um sertanista de Cuiabá muito experiente, o qual foi encarregado de deslocar grupos B ororo da região de Cuiabá e aldeá-los no atual Triângulo M ineiro. Comandando esses grupos B ororo, A ntônio Pires de $C$ ampos deveria real izar todas as ações necessárias para manter em segurança o "caminho de Goiás", protegendo os viajantes e moradores da região dos ataques dos Cayapó.

0 "problema" Cayapó não foi resolvido por Antônio Pires de Campos, flechado mortalmente pelos próprios Cayapó em 1751, nem tampouco pelos continuadores de sua insana tarefa. Os conflitos permaneceram até que se iniciasse um processo de convivência pacífica, através de al deamentos, fato que somente ocorreu após 1780, quando 0 primeiro grupo foi convencido a aceitar a viver aldeado.

Naquele momento, segunda metade do século XVIII, as jazidas auríferas apresentavam sinais de esgotamento, entrando a mineração 
em decadência. A população que se ocupava naquela atividade passou a se dispersar para outras regiões da colônia, ou para o interior da própria capitania goiana, num processo de ruralização (Palacin, 1976). Novas disputas tiveram lugar, pois agora havia de se expulsar os remanescentes Cayapó das terras desejadas para a agricultura e, principalmente, pela pecuária.

$M$ as os aldeamentos tiveram vida efêmera. 0 aldeamento construído especial mente para os Cayapó, chamado de A Ideia M aria I, foi extinto em 1813. 0 aldeamento de São J osé de M ossâmedes, construído em 1774, foi extinto em 1832 (Chaim, 1974; Ravagnani, 1987). Dessa forma, a maioria dos Cayapó não permaneceu nos aldeamentos. Como veremos a seguir, vários descimentos foram realizados a partir de princípio do século XIX para tentar recuperar os grupos que fugiam de volta para as florestas. Durante a sobrevivência dos aldeamentos, eles foram visitados por Saint-Hilaire ([1816-1822], 1975) e Pohl (1976), os quais coletaram listas de palavras Cayapó.

A pós meio século de conflitos armados entre Cayapó e "brancos", um grupo foi aldeado. 0 padre L uís A ntônio da Silva e Sousa, em texto escrito em 1812 (Silva eSousa, 1849), explicou esse processo do primeiro aldeamento da seguinte maneira: em 1778, Luiz da Cunha Menezes assumiu o governo de Goiás e, dois anos depois, enviou uma bandeira ao sertão para tentar atrair os Cayapó. A pós cinco meses na região do Alto A raguaia, ela retornou com um grupo composto por um índio idoso, seis guerreiros, suas mulheres e filhos, perfazendo um total de 36 Cayapó. A pós passarem perto de um mês na vila, foram mandados de volta para suas al deias, para convencer os demais a aceitar 0 al deamento. Chegando ao R io Claro, o vel ho preferiu permanecer, com as mulheres e crianças, num destacamento militar existente na margem daquele rio, mandando que os seis guerreiros fossem até as aldeias e chamassem os demais a al dear-se. Ordenou, também, que voltassem em oito luas. Em 29 de maio de 1781, chegaram a Vila Boa de Goiás 237 Cayapó, comandados por dois caciques, sendo batizados, em 12 de junho, 113 meninos. Para abrigálos, o governador construiu um al deamento, chamado de A Ideia M aria I. Como resultado dessa primeira redução, vieram duas outras levas, uma de 88 e, depois, mais duzentos Cayapó, perfazendo perto de seiscentos que foram al deados em M aria I (Silva e Sousa, 1849, p. 460). 
J osé M artins Pereira de A lencastre foi presidente da província de Goiás e escreveu, em 1863, um trabalho intitulado Anais da província de G oiás (Alencastre, 1979). Seu propósito foi rescrever a história da capitania a partir dos escritos do padre Silva e Sousa. Vejamos como ele explicou esse acontecimento da assim chamada pacificação dos Cayapó.

Em 15 de fevereiro de 1780, o soldado L uiz partiu da A Ideia de São José de M ossâmedes comandando uma expedição de cinqüenta homens e alguns Cayapó como intérpretes. Entrou pelo sertão do Rio Claro, procurando as vertentes do Alto A raguaia, com a intenção de pacificar os índios, levando, para isso, muitas coisas para presenteá-los. A pós cinco meses e seis dias no sertão, retornou com o vel ho R omexi, 0 qual vinha em lugar do cacique A ngraiocha, acompanhado de seis guerreiros e pessoas de suas famílias, perfazendo 36 Cayapó. Os Cayapó teriam sido recebidos com as maiores pompas pelo governador $L$ uiz da Cunha $M$ enezes. Tanto teria sido boa a recepção que uma das mulheres, chamada Punquere, ao falecer por ter vindo doente, foi sepultada na igreja. Depois de 25 dias na capital e em São J osé de M ossâmedes, 0 grupo foi mandado de volta para as suas aldeias para tentar convencer os demais a se al dear. Romexi viajou com o grupo todo até o destacamento de Pilões, ali permanecendo com as mulheres e crianças, seguindo em frente os seis guerreiros, que deveriam retornar em oito luas. E m 10 de maio, chegava à capital, Vila B oa, a notícia de que a primeira aldeia Cayapó estava no Rio Claro, de marcha para a capital, com 237 índios sob o comando dos caciques A ngraiocha e de X aquenonau. Entraram na capital em 29 de maio, ali permanecendo até 16 de julho, quando foi inaugurado 0 aldeamento de M aria I, construído às margens do Rio Fartura. Em 27 de setembro de 1781, mais uma aldeia, a do cacique Cananpuaxi, entrou no aldeamento e, em 1782, foi a vez da aldeia do cacique Pupuare aceitar a pacificação. Reunidos todos, conclui A lencastre, formavam as quatro al deias conquistadas uma povoação de 687 indivíduos, dos quais 328 eram batizados.

A s informações contidas nas cartas escritas pelo então governador da capitania de Goiás, Luís da Cunha M enezes ${ }^{4}$ mostram, entretanto, que a bandeira foi formada por cinqüenta homens que portavam armas de fogo: 26 B ororo da A Ideia de Rio das Pedras, 12 A kroá de São J osé de M ossâmedes e 12 sol dados, comandados por um cabo chamado J osé 
L uís Pereira. Foram instruídos a encontrar uma al deia, cercá-la e capturar um grupo para que fossem levados até Vila Boa para ver como era a vida civilizada. Em 21 de setembro, após cinco meses no "sertão", chegou a bandeira com um grupo de 36 pessoas, sendo destas seis guerreiros. U ma das mulheres do grupo morreu logo após a chegada. Isto indica que poderia estar ocorrendo uma epidemia entre eles. Foram recebidos com salva de artilharia e depois foram levados à igreja, onde foi celebrada uma missa. Informa o governador que obj etivava, com isso, impressionar os índios. De fato, com o fogo da artilharia demonstrava o poder do soberano; com a missa, marcava o poder da Igreja.

A pós 0 grupo passar 25 dias na capital e no aldeamento de São J osé de M ossâmedes, ordenou-se que os Cayapó voltassem para 0 "sertão" para convencer os demais a aceitar 0 aldeamento. 0 chefe mais velho reluta em voltar para as al deias.

Em 10 de maio de 1781, chegou o grande grupo de Cayapó que aceitou 0 descimento para junto dos "brancos". Conduzidos a Vila B oa, o governador fez repetir os mesmos rituais de disparar a artilharia e celebrar a missa. Permaneceram 38 dias em Vila B oa, nascendo seis crianças neste período e batizando-se 113 crianças.

Deve ter havido algum tipo de negociação entre o governador e as lideranças Cayapó, pois foram eles que escolheram o local para o novo al deamento: ficava nas margens do riacho chamado Fartura, próximo dos R ios Claro e Pilões. Com isso, poderiam permanecer em uma região com as mesmas características ambientais das áreas de suas aldeias.

$M$ as quais os motivos que teriam levado os Cayapó a aceitar viver no al deamento, após tantos anos de conflitos com os "brancos"? M inha hipótese é que pelos menos três fatores conjugados nos fornecem uma explicação: derrotas nas guerras contra os "brancos", epidemia de varíola e falta de alimentação e ocorrência de seca por dois anos (Karasch, 1981, p. 105).

$\mathrm{N}$ aquele momento, os Cayapó estavam sofrendo ataques de bandeiras organizadas a partir das três capitanias: Goiás, São Paulo e $M$ ato Grosso. Essa situação deve ter causado muitas alterações na sua população, tanto pelas mortes ocorridas pelos ataques dos "brancos" quanto pel os deslocamentos mais freqüentes, necessários diante da nova situação. A lém disso, outro fato pode tê-Ios debilitado ainda mais. Em 
1771, ocorreu uma epidemia de varíola que atingiu toda a capitania de Goiás (A lencastre, 1979, p. 342) e deve ter atingido também os Cayapó. Vimos que uma das mulheres do primeiro grupo morreu logo depois de chegar em Vila Boa. A crescente-se, também, que entre 1778 e 1780 as chuvas foram menos abundantes, podendo ter contribuído para diminuir os recursos alimentares ( $K$ arasch, 1981, p. 105). A ssim, necessitando deslocar-se com mais freqüência, abandonavam as roças plantadas sem que tivessem outras prontas para ser aproveitadas, o que pode ter causado a fome entre eles.

Os descimentos de outros grupos continuaram ocorrendo. Em 1783, chegaram à A Ideia M aria I dez guerrei ros Cayapó demonstrando interesse em trazer sua aldeia para 0 aldeamento. Voltaram para sua aldeia nas margens do Rio Grande, possivelmente à margem do Paraná, pois o documento afirma que a aldeia estava "mais na capitania de São Paulo do que n' esta de Goyaz". Em princípios de setembro chegou a M aria I a notícia de que um grande número de Cayapó estava a caminho, e alguns dias depois chegaram muitos deles. Tristão da Cunha M enezes, ${ }^{5} \mathrm{em} 1784$, confiava que existiam naquele momento na aldeia M aria I "mais de 600 homens de guerra da dita Nação Cayapó".

Essa informação da existência de seiscentos guerreiros levou vários autores a citar, a meu ver erroneamente, esse número como sendo 0 total da população Cayapó al deada em M aria I. Exemplar, neste sentido, são os trabalhos, supracitados, de Silva e Sousa (1849), Saint-Hilaire ([1816-1822], 1975), Pohl (1976), A lencastre (1979), Chaim (1974) e K arasch (1981). Tratava-se, isto sim, de mais de seiscentos guerreiros, 0 que implica, conseqüentemente, uma população maior.

0 padre D esgenettes (1906), tentando avaliar a população Cayapó do sudoeste goiano e do $\mathrm{M}$ ato $\mathrm{G}$ rosso, utilizou uma proporção de mais ou menos seis pessoas para cada guerrei ro. ${ }^{6} \mathrm{U}$ tilizando o mesmo coeficiente do padre, teríamos, então, 3,6 mil Cayapó reunidos no aldeamento de M aria I. Verswijver (1985, p. 22), através da análise do censo de 12 grupos indígenas do B rasil Central, confirmou que se pode utilizar uma proporção de quatro pessoas para cada guerreiro para calcular a população total de uma aldeia. Seguindo sua sugestão, teríamos 2,4 mil Cayapó vivendo inicialmente em $\mathrm{M}$ aria I.

Esse número alcançado a partir do coeficiente proposto por Verswijver, ainda que bastante elevado, não creio que seja absurdo. 
A lencastre afirma que os $C$ ayapó reunidos em $M$ aria I eram provenientes de quatro aldeias (A lencastre, 1979, p. 237). M as, na verdade, tratavase de um número maior que quatro aldeias. Quatro teriam sido as que viviam na região de Camapuã, na capitania de $M$ ato Grosso, enquanto outros grupos haviam chegado recentemente, das margens do R io Grande, próximo à capitania de São Paulo.

[...] aquelas quatro Aldeias de Índios da Nação Cayapó, que se achavão Aldiados na A Idea $\mathrm{M}$ aria, herão dos que habitavão as campanhas do varadouro da Camapuã, mais pertencentes a Capitania do Cuyabá do que a esta. Dos que prezentemente chegarão à dita $A$ ldeia $M$ aria são os que habitavão as margens do Rio-grande, mais na capitania de São Paulo do que d'esta de Goyaz $[\ldots]^{7}$

A umentou de tal forma a população do al deamento que começou a preocupar o novo governador de Goiás, Tristão da Cunha M enezes. Quando ele estava viajando de São Paulo para assumir o governo da capitania goiana, teve a oportunidade de ser testemunha do resul tado de um ataque Cayapó no "caminho de Goiás": eles atacaram uma tropa de mulas, matando a mulher e o primo do tropeiro, mais oito ou dez mulas e levando parte das mercadorias. ${ }^{8}$ Ficou ainda mais preocupado quando um dos grupos recém-chegados em $M$ aria I confessou a autoria do ataque à tropa de mulas.

N esse mesmo ano, existia o maior contingente de Cayapó aldeado: grupos de cinco aldeias e mais de seiscentos guerreiros. Havia um tamanho receio do que poderia acontecer com essa quantidade de guerreiros que se conjecturava que el es poderiam, com aquele contingente, rebelar-se e matar todo as pessoas "brancas" do al deamento sem maiores problemas. Esse número elevado também provocou problemas de fornecimento de comida para os Cayapó, levando a crer que o governo não se preparara para receber tantos índios de uma só vez.

Inicialmente era-Ihes fornecido carne de gado para se alimentar, mas logo esse fornecimento foi interrompido, tendo eles começado a matar reses dos moradores das fazendas próximas, mantendo, assim, 0 clima de atrito com a população "branca". Somente em 1786, portanto, cerca de quatro anos depois do início do aldeamento, foi que o governo 
criou uma fazenda para fornecer gado que pudesse abastecer 0 aldeamento. ${ }^{9}$

O utro ponto de atrito eram os grupos indígenas al deados em São J osé de M ossâmedes. Esse último al deamento foi criado em 1774 e nele foram al deados juntos A kroá, X acriabá, J avaé e K arajá. Ficava a poucas léguas de $M$ aria I, e os contatos entre os vários grupos e os Cayapó resultavam em pequenas escaramuças, por serem inimigos tradicionais, mantendo uma tensão que punha as autoridades com receio da possível explosão de um conflito entre os grupos, ou dos próprios Cayapó entre si.

A maneira como foram organizados os aldeamentos contribuiu, também, para seu declínio. A A Ideia M arial fracassou porque o governo de G oiás não tinha controle sobre a sua população. Não se tratava de um al deamento cujas regras para a permanência nele, dos índios aldeados, impedissem o acesso dos Cayapó ao seu território tradicional. A o contrário, eles circulavam constantemente entre 0 aldeamento e suas próprias aldeias. Exemplo disso são as informações fornecidas pelo diário de exploração dos R ios Claro e Pilões, levada a cabo em 1804 e 1805, com o objetivo de pesquisar a existência de ouro naquela região.

Naquele ano, em decorrência do esgotamento das minas mais antigas da capitania, o governo organizou algumas expedições para explorar a região. U ma delas explorou o Rio Claro e, por várias vezes, descobriu vestígios dos índios nas trilhas abertas por eles na floresta. Dentre os presentes na expedição, estava um Cayapó, por nome L ourenço, morador do aldeamento de Maria I. Nas cabeceiras do Rio Claro, enquanto os participantes da expedição permaneciam num acampamento montado provisoriamente para descansar, L ourenço visitou uma aldeia Cayapó e conseguiu comida para o grupo. Em outro momento, encontrouse um acampamento Cayapó não habitado, o qual, segundo Lourenço, servia como ponto de passagem dos Cayapó quando de suas perambulações pela região e quando iam de suas al deias para 0 al deamento de Maria I.

Em determinado momento, a expedição viu-se perdida na região. Sua esperança toda estava depositada na experiência do Cayapó L ourenço, para encontrar uma picada conhecida como "estrada dos índios" que seguia do aldeamento $M$ aria I para as terras Cayapó. Ficaram felizes 
ao encontrá-la e retornaram para $\mathrm{M}$ aria I, onde puderam, finalmente, restabelecer-se. ${ }^{10}$

A lém disto, no final do século X VIII não havia interesse por parte do governo português em transformar os índios em mão-de-obra, uma vez que a mineração declinava e as atividades econômicas diluíam-se para a criação de gado e para a pequena agricultura de subsistência.

Entre os motivos que também devem ter contribuído para o insucesso dos al deamentos, devemos considerar as epidemias. Segundo A lencastre (1979, p. 342), a partir de 1811 ocorreu outro surto de varíola em todo o sul da capitania. Elas certamente devem ter atingido os aldeamentos. A lém da varíola, também o sarampo os atingiu, pois em 1819 Saint-Hilaire ([1816-1822], 1975, p. 69) observou que havia al guns anos quase todos os C ayapó foram atacados "de sarampo", tendo morrido mais de oitenta. A firma ainda o naturalista francês que eles estavam contaminados por doenças venéreas transmitidas "pelos portugueses" (Saint-Hilaire [1816-1822], 1975, p. 69).

Essa situação de depopulação crescente dos aldeamentos levou as autoridades a reunir os índios dos al deamentos de M aria I e São J osé de M ossâmedes neste último, pois se afirmava que os dois estavam tão arruinados e com tão poucos índios que, reunindo-se os de ambos, perfaziam um total de $267 .{ }^{11}$

Em 1819, J ohn E. Pohl e Saint-Hilaire visitaram os aldeamentos de São J osé de M ossâmedes e M aria I. Segundo Pohl, a aldeia de M aria I estava em ruínas, sendo necessário cortar o mato com facão para poder entrar nas asas. Já São J osé de M ossâmedes ainda apresentava al guma dinâmica. No núcleo do aldeamento, viviam soldados e mestiços, enquanto os Cayapó construíram sua aldeia a uma légua de distância, próximo a suas roças. Saint-Hilaire ([1816-1822], 1975, p. 64) interpreta essa recusa a morar no aldeamento como uma rejeição dos Cayapó às casas construídas com teto alto e cobertas de telha, por acharem-nas muito frias. $\mathrm{N}$ a sua al deia, construíram as casas da maneira tradicional, cobertas com pal has. $\mathrm{N}$ as suas roças, Saint-Hilaire encontrou mulheres colhendo milho (Saint-Hilaire [1816-1822], 1975, p. 66) e também várias que carregavam cestos (chamados de jucunu) cheios de amendoim (SaintHilaire [1816-1822], 1975, p. 71).

Saint-Hilaire afirma que o diretor ainda governava seguindo a administração do Diretório pombalino. Os Cayapó eram obrigados a 
trabalhar cinco dias por semana em suas roças para plantar mantimentos para todo 0 aldeamento. A colheita feita pelos Cayapó era recolhida pelos sol dados e posteriormente di vidida entre todos os moradores, índios ou não. 0 excedente era comercializado pelo diretor do aldeamento ou pelos próprios soldados. Restava, segundo Saint-Hilaire, dois dias por semana para que os Cayapó cultivassem seus inhames e suas batatas (Saint-Hilaire [1816-1822], 1975, p. 65).

Essa situação provocava constantes fugas de Cayapó do al deamento. Para tentar recapturar os fugitivos, assim como para tentar convencer novos grupos a al dear-se, cumpriu importante papel a cayapó Damiana da Cunha.

D amiana era neta do chefe A ngraiochá e de sua mul her X uinequá (A lencastre, 1979, p. 338), sendo uma criança quando seu grupo foi aldeado em 1781. Ela exercia grande influência sobre os Cayapó e, por isso, foi utilizada pelos governadores para comandar expedições ao "sertão". Segundo K arasch (1981), ela comandou cinco expedições. A primei ra foi realizada em 1808, na cabeceira do A raguaia, de onde levou setenta índios; a segunda em 1819, na mesma região, com igual número de índios reduzidos; a terceira em 1821, com 35 índios aldeados; a quarta foi realizada em 1827, também na região do Alto A raguaia, tendo percorrido tanto a região de $\mathrm{G}$ oiás quanto do $\mathrm{M}$ ato $\mathrm{G}$ rosso, conseguindo atrair cem índios Cayapó. Na quinta expedição, em 1830, Damiana adoeceu no sertão, retornando sem conseguir levar nenhum índio e vindo a falecer logo em seguida. ${ }^{12}$

Para essa última expedição, Damiana da Cunha recebeu instruções do governador para que convencesse os Cayapó a se aldear. Caso se negassem a isto, não deveriam ser forçados, mas advertidos para que não continuassem a atacar os moradores da fazendas. Caso persistissem nisso, seriam perseguidos à força das armas. ${ }^{13}$

A pós a morte de Damiana, em 1831, começa a ocorrer fuga crescente dos restantes de Cayapó que ainda viviam em São José de M ossâmedes. Em 28 de dezembro, por exemplo, um Cayapó de nome Miguel Impocaro abandonou São J osé de M ossâmedes com toda sua família. ${ }^{14}$

Diante dessas fugas, o governador, consultando o Consel ho de Governo, decide, em 17 de janeiro de 1832, expedir mais uma bandeira formada por índios aldeados para tentar descer os índios fugidos. ${ }^{15}$ 
Comunicou-se ao vigário da aldeia; ${ }^{16}$ aprontou-se a expedição, e dois Cayapó dos que ficaram em São J osé de M ossâmedes foram até a capital, ex-Vila B oa, então já com o nome de cidade de Goiás, buscar armas e munições. ${ }^{17} \mathrm{M}$ as depois de ouvir as opiniões de um fazendeiro, por nome Pedro Gomes M achado, o qual era proprietário de terras na região do Rio Fartura, local da A Ideia M aria I, a expedição foi cancelada, em 4 de fevereiro de $1832 .{ }^{18}$

A s fugas continuaram, sendo agora incentivadas pelo irmão de Damiana da Cunha, o Cayapó conhecido pelo nome de Manuel da Cunha. ${ }^{19} \mathrm{O}$ governador tentou acabar com as fugas prendendo $\mathrm{M}$ anuel. M as não conseguiu evitá-las, de tal maneira que, em fevereiro de 1833, mandou que o vigário da al deia retornasse para a capital, pois não havia mais índios no al deamento (M B, v. 1680).

Deve-se ressaltar, no entanto, que não foram todos os Cayapó que abandonaram 0 aldeamento. A lguns deles ali permaneceram, principalmente vel hos e deficientes, além de al guns em idade de trabal ho, os quais ainda solicitaram do governo ferramentas para praticar a agricultura. ${ }^{20}$ Informações de 1846 davam conta que 0 aldeamento de São J osé de M ossâmedes já estava vazio, ${ }^{21}$ sendo extinto, oficialmente, em 1879.22 Dos últimos remanescentes Cayapó de São José de M ossâmedes, chegou até o presente notícia de dois deles que estiveram na cidade de G oiás, em 1885, e o governo Ihes forneceu al guns objetos. ${ }^{23}$

Durante 0 século XIX, intensificou-se o processo de ocupação das terras a sudoeste de Goiás, fazendo recrudescer os conflitos entre "brancos" e Cayapó. Estes eram "resolvidos" pelo embate armado entre as duas partes envolvidas, sem a interferência do Estado. 0 objetivo dos "brancos" era expulsar ou extinguir os índios.

O correu, dessa forma, um declínio gradual na sua população, de tal maneira que poucos deles viviam na região do Triângulo $M$ ineiro, quando foram encontrados pel os exploradores da Comissão G eológica e Geográfica do Estado de São Paulo.

Todo esse processo, al iado a uma concepção positivista de história e sociedade, reinante naquele início de século XX, que acreditava na fatal extinção dos povos de supostas fases culturais inferiores, levou a maioria dos autores que fizeram referência aos Cayapó a acreditar que eles caminhavam para a extinção, ou que já estavam extintos. 
Em 1940, Nimuendajú apresentou um relatório ao SPI sobre os Gorotire, afirmando que dos Cayapó apenas um grupo reduzido de cerca de trinta pessoas ainda vivia, em 1910, nas margens do Rio Grande, mas acrescentando que "H oje os K aiapó M eridionais desapareceram como tribo" (Nimuendajú, 1952, p. 427). Robert L owie, no H andbook of South American Indians (1946, p. 519), na parte referente aos Cayapó, usando como fontes de referência os relatos de Saint-Hilaire e Pohl, repete a opinião de Nimuendajú de que aquela sociedade indígena deixou de existir. Posteriormente Egon Schaden, eminente etnólogo, em 1954, também compartilhou a mesma opinião de que os Cayapó estavam extintos, baseando-se nos escritos de Lowie (Schaden, 1954, p. 397).

\section{0 ressurgimento da etnia}

$\mathrm{No}$ entanto, os estudos mais recentes indicam que estavam enganados os que acreditaram que os Cayapó estavam extintos, da mesma forma que demonstram a fragilidade da hi pótese daqueles que acreditaram que os K ayapó (setentrionais) fossem parte dos do sul que teriam se refugiado próximo do $X$ ingu.

Foi Richard H. Heelas, antropólogo inglês, quem inicialmente Iançou a hipótese de que os Panara e os Cayapó poderiam ser um único grupo. Os Panara, grupo Jê, era conhecido, anteriormente ao seu contato, como $\mathrm{K}$ reen $\mathrm{A}$ krore, nome que Ihes davam os K ayapó. Foram contatados em princípios da década de 1970 na região norte do M ato Grosso, às margens do Rio Peixoto de A zevedo. Contando inicialmente com uma população estimada em cerca de seiscentos pessoas, após dois anos de contato os Panara reduziram-se para menos de cem. Quando foram transferidos para o Parque Nacional do Xingu, sobreviviam apenas 79 pessoas. Heelas foi o primeiro antropólogo a estudá-los, realizando uma descrição etnográfica bastante detalhada, levando-se em consideração a grande depopulação ocorrida naquele momento.

A o comparar as listas de palavras Cayapó, coletadas por SaintHilai re e Pohl, em princípio do século no aldeamento goiano de São J osé de M ossâmedes, H eelas verificou a existência de termos cognatos com a língua Panara (Heelas, 1979, p. 2). A ssim, da lista de Pohl, contendo 65 termos, considera 26 como cognatos, 5 como incompreensíveis, 14 como não-conhecidos e 20 não-cognatos. Da lista de Saint-H ilaire, com 
33 termos, 19 são cognatos, 4 incompreensíveis, 3 não-conhecidos e 7 não-cognatos.

O segundo trabalho antropológico entre os Panara foi realizado por S. Schwartzman na década de 1980 (Schwartzman, 1987). Ele reexaminou as mesmas listas analisadas por H eelas e concluiu que, dos 65 termos fornecidos por Pohl, 35 são palavras si milares (52\%), enquanto o mesmo ocorre em 27 (81\%) dos 33 termos da lista de Saint-Hilaire. A ssim, da comparação das duas listas, temos que $62 \%$ das palavras são similares.

A lém das listas de Saint-Hilaire e Pohl, duas outras foram coletadas em Santana do Paranahiba, uma pequena cidade do atual $M$ ato $G$ rosso do Sul, às margens do R io Paranahiba, na confluência com o Rio G rande, onde havia um aldeamento Cayapó pelo menos até o final do século XIX. Uma delas foi coletada por K upfer (1870) e outra por Nehring (Ehrenreich, 1894), ambas da segunda metade do século XIX, mas que não foram analisadas por Heelas ou Schwartzmann. Comparando-as com as duas outras listas conhecidas, chega-se a 93\% de fonemas correspondentes entre as palavras (Luciana Dourado, comunicação pessoal, e R odrigues \& Dourado, 1993).

Schwartzmann, no entanto, apontou outras evidências possíveis da relação entre Panara e Cayapó. A forma de construir flechas, unindose pequenos segmentos de bambu até se obter o tamanho desejado; a técnica para construção de cestos; a prática de escarificação da testa com um pequeno arco e flecha para curar dores de cabeça, todas elas idênticas entre os dois grupos.

Schwartzmann concluiu que era provável que os Panara do Peixoto de A zevedo representassem um grupo de Cayapó não-assimilados que fugiu de Goiás ou do sul de M ato G rosso no final do X VIII, ou início do $X I X$. M encionou como evidência dessa hi pótese a própria tradição Panara de que seus ancestrais vieram do leste, de uma área de campo aberto, para a área de floresta fechada do Rio Peixoto de A zevedo e que os inimigos estão no leste e não no oeste (Schwartzmann, 1983, p. 256). Veremos a seguir que essa hipótese é verdadeira. 


\section{Cayapó-panara}

A quele grupo de cerca de trinta pessoas encontrado pelo Comissão Geológica, nas margens do Rio Grande, embora provocasse pouco interesse aos membros daquela expedição, felizmente atraiu a atenção de um morador de U beraba, muito curioso.

A lexandre de Souza B arbosa trabal hava, em 1911, como agrimensor, medindo as terras das fazendas da região do extremo oeste do Triângulo M ineiro, na confluência dos Rios Panarahiba e Grande, quando encontrou um grupo de Cayapó. Esse grupo vivia na aldeia de Á gua Vermelha, próximo da atual cidade de São Francisco Salles. B arbosa registrou que el es se autodenominavam Panara. Eram um grupo de apenas quatro pessoas, ainda jovens. B arbosa decidiu, então, montar um vocabulário da sua língua, passando a anotar as palavras que lhe ditavam. $M$ as a cada vez que perguntava sobre 0 significado de cada uma delas, os jovens índios diziam: "minha mãe é que sabe tudo". A mãe, reticente, não queria ir até 0 acampamento de B arbosa. Foi necessário, segundo ele, muito esforço para convencê-la. Ela chamava-se Cândida e foi descrita por Barbosa como simpática e "notavelmente inteligente". Presenteada e tratada com carinho, ela resolveu, afirma B arbosa, "ensi narme a língua". A pós ler-Ihe as palavras ditadas por seus filhos, a velha senhora corrigiu al gumas delas, acrescentando outras.

Devido a essa feliz atitude de A lexandre de Souza B arbosa, chegounos até o presente 0 vocabulário mais completo sobre a língua Cayapó. Trata-se de um conjunto de mais de setecentas palavras, acrescentado ainda da narrativa de situações de pesca e caça. A partir dela, podemos avançar a hipótese proposta por Heelas e ampliada por Schwartzmann de que Cayapó e Panara são o mesmo grupo, bem como fornecer material para os lingüistas poderem estabelecer um quadro mais detalhado das línguas indígenas existentes no $\mathrm{B}$ rasil. ${ }^{24}$

Os quadros adiante servem como exemplos comparativos entre as duas línguas, comparando-se os vocabulários de Saint-Hilaire, Pohl, os alemães K upfer e Nehring, além dos brasileiros Lemos e B arbosa com a língua Panara atual - informações extraídas de Heelas (1979) e Schwartzmann (1985). A s listas completas dos diversos vocabulários podem ser encontradas em minha dissertação de mestrado (Giraldin, 1994) bem como em meu livro (Giraldin, 1997). 
PARTES DO CORPO HUMANO

\begin{tabular}{|c|c|c|c|c|c|c|c|}
\hline Português & S.Hilaire & Pohl & Kupfer & Nehring & Lemos & Barbos a & Panara \\
\hline Cabeça & Icrian & Icrian & Ikiá & & Paquiã & Kián & Hì'kyà \\
\hline Cabelo & Iquim & Inki & Iking & Paquim & & $\mathrm{K}$ in & Hì'kì \\
\hline Cãs & & & & & & Kiánpô & Kiãpo \\
\hline Orelha & Chicré & Chuceré & Zicré & Zukré & Pacré & Çukré & Sikre \\
\hline Braço & Ipa & & & & & Ipá & Hì'pá \\
\hline Cotovelo & & & & & & Pakuçú & Pakusú \\
\hline Pescoço & & & & & & Impút & Imputi \\
\hline Nuca & & & & & & Impút & Imputi \\
\hline Perna & Ite & Ité & Zãtakríta & & & Ité & Hì'te \\
\hline Canela & & & & & & Ité & Itá \\
\hline Dente & Chua & & Ischoa & Pachuá & & Suá & Sua \\
\hline Coxa & Icria & & & & & Inkré & Hì'krè \\
\hline Mão & Chicria & & & Zukiã & Pantôte & Cykiá & Sikya \\
\hline Olhos & Intó & & & Intó & Pantó & Intó & Into \\
\hline Caolho & & & & & & Intónó & Intono \\
\hline Nariz & Chacare & & Pacré & Zãkrã & & Çâkré & Sakre \\
\hline Boca & Chape & & Sacoa & Zapé & & Çakuá & Sakwa \\
\hline Lábio & & & & & Pacôcy & Çakuá & Sakoá \\
\hline Língua & & & Zutó & & Pããtó & Çuntót & Sutóti \\
\hline Queixo & & & & & & Çakiát & Sakiáti \\
\hline Rosto & & & & & & Intó & Intó \\
\hline Peito & Chucoto & & Zucoté & & & Çukôt & Sonkôti \\
\hline Coração & & & & & & Inkôkrê & Ikokré \\
\hline Estômago & & & & & & Impá & Impá \\
\hline Umbigo & & & & & Pantóte & Çuntót & Sukowti \\
\hline Pés & Ipaa & & & & & Ipá & Hi'pa \\
\hline Calcanhar & & & & & & Pakiát & Pakiáti \\
\hline Pênis & & & Impú & & Impú & Impú & Inpu \\
\hline Escroto & & & & & Incré & Inkré & Inkré \\
\hline Vulva & & & Inzé & & Iche & Icê & Isé \\
\hline
\end{tabular}

Sociedade e Cultura, v. 3, n. 1 e 2, jan/dez. 2000, p. 161-184 
TERM OS DE PARENTESCO (afins e consangüíneos)

\begin{tabular}{|l|l|l|l|l|l|l|l|}
\hline Português & S.Hilaire & Pohl & Kupfer & Nehring & Lemos & Barbosa & Panara \\
\hline Avô & & & Uté & & & Tapúpiâ & Topiépié \\
\hline Avó & & & Topopié & & & Tatúpiâ & $\begin{array}{l}\text { Twapié } \\
\text { Wètung }\end{array}$ \\
\hline Mãe & & Unisi & Kuinzí & & Tia & Tíkâ & $\begin{array}{l}\text { Wungsi } \\
\text { Nàpié }\end{array}$ \\
\hline Pai & & Usum & Hokió & & Uxum & Uçúm & $\begin{array}{l}\text { Wésum } \\
\text { Sumpié }\end{array}$ \\
\hline Filho & & & Ipó & & & Ipán & Pã \\
\hline Neto & & & & & & Tánpiâ & Tàmpiè \\
\hline Marido & & & & & & Pínpiâ & Impimpié \\
\hline Esposa & & & & & & Intié & Insipié \\
\hline Cunhado & & & & & & Kiântú & Kyentàmpié \\
\hline Sogra & & & & & & Kokrípiâ & Kripié \\
\hline Genro & & & & & & Pôkiá & Punkya \\
\hline Sobrinho & & & & & & Pakré & Pakre \\
\hline Tio (tia) & & & Bitó & & & Citón & Tõ \\
\hline
\end{tabular}

\section{OUTROS}

\begin{tabular}{|c|c|c|c|c|c|c|c|}
\hline Português & S.Hilaire & Pohl & Kupfer & Nehring & Lemos & Barbosa & Panara \\
\hline Homem & Impuaria & & Puará & Impú & Ipé & Impúará & Impúara \\
\hline Mulher & Intiera & & Intiará & Inká & Insipiá & Intierá & Inkyara \\
\hline Água & Inco & & Pinkó & Inkó & & Inkô & Ingkô \\
\hline Bruto & & & & & & Çampánón & San-pa-no \\
\hline Carne & Jóbo & $\begin{array}{l}\text { Potina } \\
\text { Schain }\end{array}$ & $\mathrm{Hi}$ & & & In, $\mathrm{C}$ in & Sì, Yìn \\
\hline Comer & & Lempania & & & & Tikukrén & $\begin{array}{l}\text { Kukré } \\
\text { Cikukrén } \\
\text { Tikrén } \\
\end{array}$ \\
\hline Faca & & Kaascha & & & Coacha & Káaçôa & Kàyasà \\
\hline Casa & Uncua & Kikré & & & & Kukré & $\begin{array}{l}\begin{array}{l}\text { Kokre } \\
\text { Inkuá }\end{array} \\
\end{array}$ \\
\hline Rio & Pupti & Pupti & & & & Pakré & Pakre \\
\hline Frio & & Kiuli & Kihui & & & Ikíh kir & Kiu \\
\hline
\end{tabular}




\begin{tabular}{|l|l|l|l|l|l|l|l|}
\hline Português & S.Hilaire & Pohl & Kupfer & Nehring & Lemos & Barbosa & Panara \\
\hline Morrer & & Itu & & & & Iútú & Intù \\
\hline Dor & & & & & & Titunçá & Sonsá \\
\hline Peixe & Tépo & Tepo & & Tápe & & Tép & Tepi \\
\hline Chuva & & Inta & Intá & & & Intá & Inta \\
\hline Gostoso & & & & & & Nacicí & Na-si-si \\
\hline Arma & & Atona & & Atóma & & Atóme & Ató \\
\hline Pau & Poré & Imromu & & & & Pêr & Pèri \\
\hline Terra & Cúpa & Cupa & & & & Kypa & Kupa \\
\hline Cachorro & & Ropu & Hióp & & & Ióp & Yôpu \\
\hline Veado & Impó & Inpoti & Impó & Impõ & Impó & Impó & Inpô \\
\hline Cutia & & & & & & Ikiánnacê & Kyenasã \\
\hline Milho & & Muschu & & & & Môcê & Môsu \\
\hline Amendoim & & & & & & Çãtí & Sã'ti \\
\hline Anta & Icrite & & Kiúte & Idschutá & Hiute & Kiút & Kyùti \\
\hline
\end{tabular}

Procurei destacar esse aspecto lingüístico do documento histórico deixado por A lexandre de Souza B arbosa, por ser o mais evidente no texto do autor, como se verá adiante. A importância desse vocabulário coligido por ele amplia-se para além das fronteiras dos estudos lingüísticos, por fornecer informações sobre terminologia de parentesco que podem nos auxiliar em estudos comparativos tanto dos Cayapó-Panara com os seus descendentes atuais (Panara do Peixoto de A zevedo), quanto aos demais povos de língua Jê. A lém disso, B arbosa nos fornece al gumas informações sobre o processo histórico vivido pelos Cayapó-Panara no Triângulo $M$ ineiro no final na segunda metade do século X IX e princípio do século XX. Podemos exemplificá-lo pelo processo de expropriação das suas terras, quando, em 1910 (aproximadamente), o governo converteu em propriedades individuais o território pertencente à Aldeia de São Francisco de Salles.

A inda que algumas das afirmações de Alexandre de Souza B arbosa proporcionadas por suas incursões pelo campo da arqueologia, antropologia física e dos estudos sobre línguas atualmente possam ser facilmente contestadas, em vista dos desenvolvimentos naquel as diversas 
disciplinas científicas, elas nos revelam o quanto era "curioso" nosso autor e o quanto estava informado das discussões contemporâneas (final de século XIX e início do XX) existentes no B rasil.

D essa forma, acredi to que seria muito oportuna uma iniciativa de trazer a público esse importante documento, um caso raro e exemplar para nos auxiliar no resgate da presença e agência histórica dos grupos indígenas nessa região do B rasil. Com o auxílio de informações como as de A lexandre de Souza Barbosa, foi possível relacionar dois grupos indígenas, os Panara e Cayapó, tendo em vista que os últimos eram considerados extintos.

Essas informações deixam claro que a pesquisa em arquivos revelam enormes e agradáveis surpresas ao pesquisador interessado em recuperar todos os agentes históricos de nosso passado. As pesquisas mais recentes, desenvolvidas pela historiadora Sônia M aria Fontoura, pesquisadora do A rquivo Público de U beraba, demonstram que podem existir descendentes daqueles Cayapó vivendo no interior do Triângulo Mineiro.

Como tanto as informações documentais, quanto as tradições orais indicam que os $C$ ayapó-Panara realizaram um deslocamento migratório do Triângulo $\mathrm{M}$ ineiro para o $\mathrm{M}$ ato Grosso, restam-nos algumas indagações: como isto teria corrido? A inda não o sabemos. Qual a relação entre os Cayapó-Panara do Triângulo M ineiro com aqueles que viviam em Santana do Paranaíba, no lado mato-grossense do Rio Paranaíba? Questão também ainda não respondida.

Q uando iniciei minhas pesquisas sobre os K ayapó do sul, visando a minha dissertação de mestrado na Unicamp, em conversas com pesquisadores conhecedores da região e da história daqueles índios, por várias vezes disseram-me que não havia documentação outra sobre eles, exceto aquela deixada pelos agentes coloniais da capitania e depois província de Goiás. U ma intuição (daquela própria ao exercício da investigação) levou-mea acreditar que um grupo tão importante na história colonial brasileira não teria desaparecido sem deixar sinais.

Tive a felicidade de ser "premiado" com meu "encontro" com o contato que A lexandre de Souza B arbosa teve com os Cayapó-Panara no começo do século $X X$. Espero que outros pesquisadores se lancem nos desafios dessa "aventura histórico-antropológica". A s informações 
do livro de B arbosa oferecem pistas sugestivas quanto a isso. A credito que novas descobertas certamente surgirão.

\begin{abstract}
In the history of the ocapation of the Brazilian Center-West, above all the area of Goiás, the Indians Cayapó appear as one of the indigenous people that offered larger resistance to the fixation of the no-indigenous ones in the area. The few historical information on them gave them as an extinct people starting from the beginning of the century XX. In this article, however, I present dbamental sources that indicates that Cayapó is the ancestors of arrent Panara (that live in the south of the state of Pará). As evidence of this relationship, I present linguistic data, through an excellent vocabulary of Cayapó gathered by a resident of the city of Uberaba (NG), in 1918.
\end{abstract}

Key words: indigenous history; Southem Cayapó; Panara; Central Brazil.

\title{
Notas
}

1. Utilizo o termo Cayapó com " $c$ ", e não com "k", convencional na antropologia, no sentido de distinguir entre os grupos "do norte" e "do sul". N este artigo, o termo Cayapó, com "c", será utilizado sempre que se referir aos antepassados dos atuais Panara.

2. COMISSA O GEOGRA PHICA E GEOLOGICA DO ESTADO DE SÃ O PAULO (1910). Explorações do Rio G rande e de seus afluentes. São Paulo, 1913. Esta foto pode ser vista na capa de meu livro (Giraldin, 1997).

3. O qualificativo geográfico ("do sul", "meridional") é utilizado neste caso para distingui-lo do seu outro grupo homônimo, designado como Kayapó setentrional, ou do norte.

4. Revista do Instituto Histórico e G eográfico Brasileiro (doravante RIHGB), v. 84 , p. 135-151.

5. Instituto Histórico e Geográfico Brasileiro. Conselho Ultramarino 1.2.7. (doravantelHGB-CU).

6. "Os Cayapós, que dominão o Rio Verde, R io B onito e J atahy, podem fornecer de 200 a 300 arcos, o que inculca uma população de 1.500 a 2.000 almas" (Desgenettes, 1906, p. 223).

7. IHGB-CU 1.2.7.

8. RIHGB, v. 84, p. 154.

9. M useu das B andeiras (doravante M B ), v. 395 f. $64 \mathrm{v}$.

10. RIHGB , v. 84, p. 198-219. 
11. M B, v. 1680.

12. A té agora não se sabia o resultado numérico dessa expedição. U ma portaria de 23-09-1821 mandava "dar alimentos para os 35 Cayapó" que estavam vindo al dear-se, comandados por Damiana da Cunha (M B , v. 1680).

13. A rquivo Histórico Estadual de Goiás (doravante AHE-GO). Livro 100, p. $72 \mathrm{v}-73$.

14. AHE-GO, livro 40, p. 45.

15. MB, v. 1683.

16. AHE-GO, livro 40, p. 45v.

17. AHE-GO, livro 107, p. 20v.

18. AHE-GO, livro 40, p. 46v.

19. $M$ anuel foi diretor da aldeia de São José de Mossâmedes, sendo preso quando incentivava essas fugas (A HE-GO, livro 40, p. 50v).

20. MB, v. 1680 .

21. AHE-GO, livro 191, p. 12.

22. AHE-GO, livro 606, p. 184.

23. MB , v. 1682.

24. Encontrei esse rico documento no Instituto Histórico e G eográfico B rasileiro quase por acaso. Resolvi consultar as gavetas do fichário por assunto. A pesar de saber que os Cayapó tinham sido sempre tratados por esse termo, resolvi procurar pelo assunto Panara. Fiquei extasiado quando localizei esse documento com a entrada Panara. T ratava-se do manuscrito de A lexandre de Souza B arbosa, ali guardado desde 1918 (IHGB, lata 188, doc.39). Posteriormente, fui verificar por que esse documento não havia sido mencionado nos catálogos do IHGB, os quais publicam a relação de documentos recebidos por aquele instituto. Verifiquei que, por um erro de ortografia, no catálogo consta Paraná e não Panara.

\section{Referências}

ALENCA STRE, J. M . Pereira de. Anais da Província de G oyas (1863). Goiânia: Oriente, 1979.

CASTELNAU, Francis. Expedições às regiões centrais da América do Sul. São Paul o: Nacional, 1949, 2 vols.

CHAIM , M arivone M atos. Os aldeamentos indígenas na capitania de $G$ oiás. Goiânia: Oriente, 1974. 
DESGENETTES, Pe. Raimundo Henrique. Os Índios Cayapós. Revista do Instituto Histórico e G eográfico Brasileiro, LXVII, 1906. p. 217-225.

EHRENREICH, Paul. Divisão e distribuição das tribos do $B$ rasil, segundo 0 estado atual dos nossos conhecimentos. Revista da Sociedade de G eographia do Rio de J aneiro, 1982. 8(1), p. 30-55.

Berlin, 1984.

Nehring: Sud-Cayapó. Materialien zur Sprachenkunde Brasiliens.

GIRA LDIN, Odair. Cayapó e Panara. Luta e sobrevivência de um povo. 1994. Dissertação (M estrado) - U niversidade de Campinas, Campinas.

Cayapó e Panará. Luta e sobrevivência de um povo Jê no Brasil Central. Campinas: Editora da U nicamp, 1997.

HEELAS, Richard H. The social organization of the Panara. A Gê tribe of Central Brazil. 1979. Tese (PhD) - Oxford U niversity.

KA RA SCH, M ary. Damiana da Cunha: catechist and sertanista. In: SWEET, D. G.; NASH, G. (ed.) Struggle and survival in Colonial América. California: University of California Press, 1981. p. 102-119.

KUPFER, Dr. DieC ayapó-Indianer in der Provinz M atto-Grosso. Zietschrift der Gesellschaft fur Erdkunde zu Berlin, V, B erlin, 1870.

LOWIE, Robert. The Southern Cayapó. Handbook of South American Indian. N ew Y ork: Cooper Square Publishers Inc., 1946, v. 1.

MACHADO DE OLIVEIRA, José Joaquim. Os Caiapós: sua origem; descobrimento; acommetimentos pelos mamelucos... Revista do Instituto Histórico e G eográfico Brasileiro, XXIV, p. 491-524, 1862.

NEME, Mário. Dados para a história dos índios Caiapós. Anais do M useu Paulista, 23, p. 1010-147, 1969.

NIM UENDAJÚ, Curt. Os Gorotire. Revista do M useu Paulista - Nova Série, VI, p. 427-453, 1952.

PA LA CIN, L uís G. G oiás: 1722-1822. Goiânia: Oriente, 1976.

POHL, J ohann E manuel. Viagem ao interior do Brasil (1817-1821). São Paulo: EDUSP/B H, Itatiaia, 1976.

PRA D O J r., Caio. F ormação do Brasil contemporâneo. São Paulo: B rasiliense, 1992.

RAVA GNA NI, Osvaldo M. Aldeamentos oficiais goianos. A raraquara: Dep. de A ntropologia/U nesp, 1987. (Mimeo.)

RIBEIRO, Darcy. O síndios e a civilização. São Paulo: Círculo do Livro, 1989. 
RODRIGUES, A ryon D.; D OURA D O, L uciana. Panara: identificação lingüística dos K ren-A karore com os Cayapó do Sul. In: REU NIÃ O A NUA L DA SBPC, 45, 1993. A nais... p. 505.

SA INT-HILA IRE, A uguste. Viagem à província de G oiás. São Paulo: EDUSP/ BH, Itatiaia, [1816-1822], 1975.

SCHA DEN, Egon. Os primitivos habitantes do estado de São Paulo. Revista de História, 18, p. 396-411, 1954.

SILVA E SOUSA, Pe. Antonio Luis da. M emória sobre o descobrimento, governo, população e cousas mais notáveis da Capitania de Goiás. Revista do Instituto Histórico e G eográfico Brasileiro, X II, p. 429-510, 1849.

SCHWA RTZMAN, Stephen. The Panara of the Xingu National Park; The transformations of a society. 1987. Tese (PhD) - U niversity of Chicago.

VERSWIJVER, G. Considerations on M $\widetilde{e}$ krangnoti Warfare. 1985. Tese (PhD) - Rijksuniversiteik, Bélgica. 